\title{
After 10 Years: Back to Undergraduate Research Advisors
}

\author{
C. C. Chancey \\ University of Northern lowa \\ Cedar Falls, lowa 50614-0150 USA
}

This happens often enough so it's easy to imagine: You're mentoring an undergraduate in a research project and she's doing well. You and she talk about writing up the research, and you ask for a written report. You consider this more a matter of practice for her than a first draft of a paper. After all, she's an undergraduate and hasn't yet learned how to write scientific prose. You write the draft, especially if her project is part of a larger research effort. Maybe you decide to include her research results within one section of the draft. Still, she worked hard and did a nice job and her reward is co-author status on an eventual research paper in the standard literature.

Not bad. You've invested your time and knowledge in helping an undergraduate take the first step up on the professional ladder. She's very proud of her achievement, as she should be, and you're pleased that she's confirmed in her desire to attend graduate school. What could be better?

Considering that this is a truly happy outcome, it seems perverse to argue that a better outcome should be envisioned. But let's be perverse. You and I know that the research effort involves more than completing a research project (especially since completion of a research stage is often somewhat arbitrary-funding proposal deadlines, academic schedules, etc., all come into play). Research involves organizing and writing appropriate prose, followed by the give and take of peer review. Is this too much for an undergraduate researcher?

Yes it might be, especially if the time interval between research and publication is a year or more. Undergraduates are necessarily on a limited lease as research participants-it will take graduate school to pin them down to a longer term of involvement.

So, what's to be done? Is it really true that undergraduate involvement in the full research process, although a good thing just isn't permitted by circumstances? No. The American Journal of Undergraduate Research provides a venue suitable for undergraduate researchers and their research advisors.

AJUR is intended for original articles with undergraduates as sole or first authors. This means that there is far more involvement of referees and editors in offering advice about writing style and organization during the review process. Referees-professional scientists, mathematicians, engineers, and academicsprovide feedback by e-mail, and the editorial goal is a two-week response time to a submission. Editors want to help each student achieve a clear and coherent exposition, and they understand that compromises might be necessary in deciding if supplemental research is an option. Students' research mentors are kept informed of the proposed paper's status, and they receive copies of all correspondence if they are co-authors.

AJUR provides undergraduate researchers with valuable experienceexperience that will help them be better writers in graduate school or professional life. The Journal, like any professional publication, requires authors to agree to publish in AJUR, but it will not stand in the way of research mentors who wish to incorporate their students' research results into reports in the standard professional literature.

AJUR is designed as a fully rounded research journal for undergraduates, and it should be considered as representative of the introductory level of the standard research literature 